\title{
The inhibitory effect of intestinal infusions of unsaturated long-chain fatty acids on forestomach motility of sheep
}

\author{
BY T. NICHOLSON AND SHADIA A. OMER \\ Department of Veterinary Physiology and Pharmacology, University of Liverpool, \\ PO Box 147, Liverpool L69 3BX
}

(Received 24 May 1982 - Accepted 10 February 1983)

1. Emulsions of $\mathrm{C}_{18}$ unsaturated fatty acids (FA) were infused for $2 \mathrm{~h}$ into the intestine of conscious sheep while motility of the reticulum and rumen was recorded.

2. Statistically-significant depression of motility was found when 3 or $5 \mathrm{~g} \mathrm{FA} / \mathrm{h}$ were infused. At $1 \mathrm{~g} / \mathrm{h}$ there were minor disruptions of motility.

3. The inhibitory potency was not related to the extent of unsaturation of the FA.

4. Receptors mediating the inhibitory effect were postulated to be distal to the iliac fexure of the duodenum, but the possible role of bile and pancreatic juice is discussed in relation to this problem.

5. The probability that the effect was hormonally mediated is discussed.

The depot fat of ruminant animals contains a higher proportion of saturated fatty acids than that of simple-stomached animals (Christie, 1978). This is so in spite of the high content of unsaturated fatty acids in the usual diet of ruminants. These dietary fats are hydrolysed and the fatty acids hydrogenated in the rumen so that the fatty acids eventually presented to the small intestine are predominantly in the saturated form (Garton, 1977). It has been demonstrated that administration of unsaturated fatty acids intraduodenally may increase the extent of unsaturation of the depot fats (Ogilvie et al. 1961). This raises the possibility that the composition of ruminant body fat might be altered if a greater delivery of unsaturated fatty acids to the duodenum could be achieved. Attempts have been made to do this by encapsulating lipids in an insoluble protein coat which can be broken down in the abomasum, liberating the lipid which will thus have escaped rumen alteration. In a number of the experiments which have been reported (e.g. Faichney et al. 1973; Dinius et al. 1974, Bines et al. 1978) the intake of food was reduced when large quantities of supplement were added. Among the possible causes of such a limitation on food intake are adverse effects of free lipid on rumen fermentation, supply of energy beyond that which could be utilized, or the liberation from the alimentary canal of hormones capable of affecting satiety either by action on the central nervous system or on the activity of the stomach.

Some observations have shown that intraduodenal fats or fatty acids may depress the motility of the forestomach of sheep (Titchen et al. 1966; McLeay, 1967) and goats (Ehrlein $\&$ Hill, 1970). This in itself would be expected to affect food intake adversely. This problem has received much less attention than has the effect of intraduodenal fats on motility of the simple stomach, particularly in the dog and man. The work reported here indicates that certain unsaturated fatty acids infused into the duodenum of sheep as emulsions inhibited the motility of the reticulum and rumen. No clear evidence of a correlation between potency and extent of unsaturation was obtained. The early part of the duodenum appeared not to contribute to this inhibitory effect, the receptive region of the intestine being beyond the iliac flexure of the duodenum. 


\section{MATERIALS AND METHODS \\ Animals and surgical preparation}

Eight mature, castrated male, Clun Forest sheep were used. All surgery was carried out with aseptic precautions. General anaesthesia was induced with intravenous sodium pentobarbitone and maintained with a cyclopropane and oxygen mixture given by closed circuit via an endotracheal tube. Each sheep had a rumen cannula fitted in the left sub-lumbar fossa using the two-stage method of Jarrett (1948). Each sheep was also fitted with a simple duodenal cannula inserted $50 \mathrm{~mm}$ from the pylorus and exteriorized on the right flank. The cannulas used were of polytetrafluorethylene (PTFE) measuring $53 \times 15 \mathrm{~mm}$ internally. In two of the sheep, at the same operation (sheep nos. 227 and 228), and in two more at a later date (sheep nos. 225 and 226), a re-entrant fistulation of the duodenum was also performed. The duodenum was transected just proximal to the iliac flexure and, therefore, beyond the point of entry of the bile and pancreatic duct. Similar PTFE cannulas were fitted into the two ends of the transected gut and linked outside the body.

Sheep with a re-entrant cannulation were housed in metabolism cages (Harrison, 1974) but all others were kept in individual pens. They were given $1000 \mathrm{~g}$ hay daily at 17.00 hours, water and a salt lick being always available. After removal of sutures the sheep were introduced to the experimental routine. Each day at 09.00 hours they were placed in a small stand with straps to prevent them lying down, but not sufficiently tight to suspend them. The period of training was continued until the procedures were well tolerated.

\section{Motility recording and fatty acid infusions}

Motility of the reticulum and rumen was recorded by introducing balloons $(40 \times 15 \mathrm{~mm})$ made from the fingers of polyethylene gloves attached to vinyl tubing through the rumen cannula which was then sealed with a rubber bung. The vinyl tubes were connected to pressure transducers (UP2; Ether) and these in turn were connected to the recorder (M19; Ormed, Welwyn Garden City, Herts). The balloons were lightly inflated with $2 \mathrm{ml}$ air. The activities of the reticulum and rumen dorsal sac were always recorded, and sometimes that of the ventral sac of the rumen was also recorded. Recording of motility, which began at least $0.5 \mathrm{~h}$ before any infusion started, was continued for the duration of the infusion and for at least $2 \mathrm{~h}$ thereafter.

Infusions via the duodenal cannulas were all made at $1 \mathrm{ml} / \mathrm{min}$ with a pump (WatsonMarlow, Falmouth, Cornwall) for $120 \mathrm{~min}$ so that a constant volume of $120 \mathrm{ml}$ was infused in each experiment. The order of administration of treatments was randomized and a minimum of $1 \mathrm{~d}$ of rest was allowed between experiments.

\section{Experimental procedures}

The first series of experiments was with sheep (nos. 225, 226, 229, 237, 215 and 239) having a rumen cannula and a simple duodenal cannula. Each sheep received each treatment and a control infusion. The control infusion was $2.5 \mathrm{~g}$ gum acacia (BDH Chemicals Ltd, Poole, Dorset) dissolved in water. The other treatments were emulsions of fatty acids with gum acacia and water made up as follows: fatty acid-water-gum acacia $(4: 2: 1$, by wt), then diluted with water to the final volume of $120 \mathrm{ml}$ in a domestic blender. The fatty acids were incorporated in three amounts (g): 2,6 or 10. The fatty acids used were: oleic acid of approximately $92 \%$ purity (iodine value $86-93$ ) and linoleic acid of approximately $70 \%$ purity (iodine value approximately 155 ) both supplied by BDH Chemicals Ltd; and linolenic acid of approximately $80 \%$ purity (with approximately $20 \%$ linoleic acid, iodine value not given) supplied by Fluka, Germany. Sheep nos 225 and 226 also had recordings made of reticulo-rumen motility without any infusion to check that the control infusion of gum acacia was without effect. 
The second series of experiments was with four sheep (nos 225, 226, 227, 228) having a re-entrant cannulation of the duodenum. A control infusion of gum acacia solution was made through the simple cannula with the re-entrant cannula connected. Similarly, infusions of emulsions of either $10 \mathrm{~g}$ oleic acid or $10 \mathrm{~g}$ linoleic acid were made (route 1 ). Infusions of these emulsions were also made either via the simple cannula with the re-entrant loop disconnected (route 2), so that only the proximal duodenum was perfused, or through the distal cannula of the disconnected re-entrant loop (route 3) so that the proximal duodenum was not perfused.

\section{Analysis of the recordings and statistics}

For the first series of experiments the reticulum activity was expressed as the total number of reticulum complexes occurring during the $2 \mathrm{~h}$ infusion period and, separately, the total number during the $2 \mathrm{~h}$ following the infusion. All complexes were included irrespective of whether they were monophasic, biphasic or triphasic. Triphasic complexes indicated that rumination was occurring. The number and duration of the reticulo-rumen cycles associated with rumination were determined for each of the infusion periods. In addition, the recordings were examined to determine whether rumen motility was affected in a similar way to reticulum motility and whether the balance of primary and secondary contractions of the rumen was altered. For the second series of experiments the total number of reticulum complexes during the infusion period was determined.

Statistical procedures used were a parametric analysis of variance (Snedecor \& Cochran, 1967) and a non-parametric analysis of variance by ranking (Wilcoxon \& Wilcox, 1964).

\section{RESULTS}

The sheep showed no ill effects either during or after any of the experiments. Food intake and faecal appearance remained normal. As described previously, all sheep in both experiments received control infusions of gum acacia solution. Two of the sheep (nos. 225 and 226) had recordings of forestomach motility made in three different control situations: (a) when prepared with a simple duodenal cannula and with no infusion, $(b)$ when similarly prepared and with infusion of gum acacia, $(c)$ after establishment of a re-entrant cannula and with an infusion of gum acacia through the simple cannula while the re-entrant cannula was connected. The analysis of these three control situations is shown in Table 1 and indicates a considerable extent of consistency in the motility recorded at this time of day, and that infusion of the gum acacia solution did not affect the motility. The results of analysing the motility of the reticulum during the infusion period and during the post-infusion period for all nine treatments and the control are shown in Table 2. Examination of the

Table 1. Reticulum activity of two sheep during various control recordings

(The total number of reticulum complexes and the mean interval between in seconds with their standard deviations)

\begin{tabular}{|c|c|c|c|c|c|c|c|c|c|}
\hline \multirow{3}{*}{$\begin{array}{l}\text { Sheep } \\
\text { no. }\end{array}$} & \multirow{2}{*}{\multicolumn{3}{|c|}{ No infusion }} & \multicolumn{6}{|c|}{ Gum acacia infusion $(2.5 \mathrm{~g}$ in $120 \mathrm{ml})$} \\
\hline & & & & \multicolumn{3}{|c|}{$\begin{array}{l}\text { Simple duodenal } \\
\text { cannula only }\end{array}$} & \multicolumn{3}{|c|}{$\begin{array}{c}\text { After fitting } \\
\text { duodenal re-entrant } \\
\text { cannula }\end{array}$} \\
\hline & $n$ & Mean & $\mathrm{SD}$ & $n$ & Mean & SD & $n$ & Mean & SD \\
\hline 225 & 100 & $71 \cdot 3$ & $14 \cdot 3$ & 105 & $68 \cdot 7$ & $13 \cdot 5$ & 98 & $70 \cdot 4$ & $17 \cdot 4$ \\
\hline 226 & 128 & 55.8 & $7 \cdot 1$ & 118 & 55.9 & $6 \cdot 4$ & 106 & 61.8 & $10 \cdot 2$ \\
\hline
\end{tabular}


Table 2. Reticulum activity in $2 \mathrm{~h}$ periods during which $2-10 \mathrm{~g}$ of different fatty acids were infused and the subsequent $2 \mathrm{~h}$ recovery period

(The significance of differences between each treatment and the control was determined from a two-way analysis of variance by ranking)

\begin{tabular}{|c|c|c|c|c|}
\hline \multirow[b]{3}{*}{$\begin{array}{c}\text { Treatment } \\
\text { (g fatty acid infused) }\end{array}$} & \multicolumn{4}{|c|}{ Total no. of reticulum complexes } \\
\hline & \multicolumn{2}{|c|}{ Infusion period } & \multicolumn{2}{|c|}{ Recovery period } \\
\hline & $\begin{array}{l}\text { Mean } \\
(n 6)\end{array}$ & Range & $\begin{array}{c}\text { Mean } \\
(n 6)\end{array}$ & Range \\
\hline $\begin{array}{l}\text { Control } \\
2\end{array}$ & 1112 & $98-133$ & $116 \cdot 0$ & $101-140$ \\
\hline $18: 1$ & $87.0 \mathrm{NS}$ & $60-125$ & $109 \cdot 3 \mathrm{NS}$ & $79-123$ \\
\hline $18: 2$ & $101 \cdot 7 \mathrm{NS}$ & $67-126$ & $103.8 \mathrm{NS}$ & $69-123$ \\
\hline $18: 3$ & $100 \cdot 5 \mathrm{NS}$ & $78-115$ & $105 \cdot 7 \mathrm{NS}$ & $77-126$ \\
\hline \multicolumn{5}{|l|}{6} \\
\hline $18: 1$ & $44 \cdot 3^{* *}$ & $29-53$ & $83.8 \mathrm{NS}$ & $61-108$ \\
\hline $18: 2$ & $86 \cdot 2 \mathrm{NS}$ & $30-143$ & $65 \cdot 8^{*}$ & $21-108$ \\
\hline $18: 3$ & $49 \cdot 2 * *$ & $15-74$ & $40 \cdot 7^{* * *}$ & $9-92$ \\
\hline \multicolumn{5}{|l|}{10} \\
\hline $18: 1$ & $46 \cdot 0^{* *}$ & $14-106$ & $44 \cdot 2^{* *}$ & $7-83$ \\
\hline $18: 2$ & $38 \cdot 8^{* *}$ & $10-80$ & $51 \cdot 0^{* *}$ & $0-106$ \\
\hline $18: 3$ & $44 \cdot 2^{* *}$ & $11-77$ & $20 \cdot 8^{* *}$ & $0-75$ \\
\hline
\end{tabular}

NS, not significant. ${ }^{*} P<0.05,{ }^{* *} P<0.01$.

Table 3. Rumination activity in $2 \mathrm{~h}$ periods during which 2-10 $\mathrm{g}$ of different fatty acids were infused

\begin{tabular}{|c|c|c|c|c|c|c|}
\hline \multirow{2}{*}{$\begin{array}{c}\text { Treatment } \\
\text { (g fatty acid infused) }\end{array}$} & \multicolumn{3}{|c|}{ No. of rumination cycles } & \multicolumn{3}{|c|}{ Duration of rumination cycles (s) } \\
\hline & Mean & Range & $n^{*}$ & Mean & SD & $n^{\dagger}$ \\
\hline Control & $40 \cdot 3$ & $17-83$ & 6 & $49 \cdot 5$ & $8 \cdot 3$ & 242 \\
\hline \multicolumn{7}{|l|}{2} \\
\hline $18: 1$ & $16 \cdot 3$ & $11-21$ & 4 & 49.9 & 7.4 & 65 \\
\hline $18: 2$ & $29 \cdot 6$ & $3-58$ & 5 & $46 \cdot 8$ & $10 \cdot 3$ & 148 \\
\hline $18: 3$ & $33 \cdot 2$ & $9-58$ & 6 & $52 \cdot 8$ & $8 \cdot 8$ & 199 \\
\hline \multicolumn{7}{|l|}{6} \\
\hline $18: 1$ & $5 \cdot 5$ & $5-6$ & 2 & $45 \cdot 3$ & $7 \cdot 3$ & 11 \\
\hline $18: 2$ & 16.5 & $8-25$ & 2 & 52.5 & $10 \cdot 4$ & 33 \\
\hline $18: 3$ & 18.0 & $9-37$ & 4 & 48.9 & $11 \cdot 1$ & 72 \\
\hline \multicolumn{7}{|l|}{10} \\
\hline $18: 1$ & 7.5 & $4-16$ & 4 & $46 \cdot 4$ & $12 \cdot 1$ & 30 \\
\hline $18: 2$ & 13.0 & $11-17$ & 3 & $50 \cdot 7$ & $12 \cdot 9$ & 39 \\
\hline $18: 3$ & 11.0 & $10-12$ & 3 & $50 \cdot 4$ & $10 \cdot 4$ & 33 \\
\hline
\end{tabular}

* No. of sheep showing rumination.

$\dagger$ No. of rumination cycles analysed: all cycles in all sheep.

individual records showed that some quite obvious but short-lived inhibitory responses occurred with the lower quantities of fatty acid infusions. These were not sufficient to show up as statistically significant but, nevertheless, Table 2 reveals that a depression of motility occurred in some of the sheep. A further observation in some of the sheep, which cannot be conveyed by tabulated values, is that at all infusion levels the reticulum motility was 
Table 4. The no. of rumen $(R m)^{*}$ and reticulum $(R t)$ contractions recorded for sheep no. 229 in successive 20 min periods within the $2 \mathrm{~h}$ infusion periods during which $10 \mathrm{~g}$ different fatty acids were infused

\begin{tabular}{|c|c|c|c|c|c|c|c|c|c|c|c|c|}
\hline \multirow{2}{*}{$\begin{array}{c}\text { Period of infusion (min) } \\
\text { Treatment } \\
\text { (fatty acid infused) }\end{array}$} & \multicolumn{2}{|c|}{$0-20$} & \multicolumn{2}{|c|}{$20-40$} & \multicolumn{2}{|c|}{$40-60$} & \multicolumn{2}{|c|}{$60-80$} & \multicolumn{2}{|c|}{$80-100$} & \multicolumn{2}{|c|}{$100-120$} \\
\hline & $\mathrm{Rm}$ & $\mathbf{R t}$ & $\mathbf{R m}$ & $\mathbf{R} \mathbf{t}$ & $\mathrm{Rm}$ & $\mathbf{R t}$ & $\mathrm{Rm}$ & $\mathbf{R t}$ & $\mathrm{Rm}$ & $\mathbf{R t}$ & $\mathrm{Rm}$ & $\mathbf{R} \mathbf{t}$ \\
\hline Control & 41 & 27 & 34 & 22 & 33 & 22 & 34 & 23 & 35 & 23 & 34 & 22 \\
\hline $\begin{array}{l}18: 1 \\
18: 2\end{array}$ & $\begin{array}{l}24 \\
27\end{array}$ & $\begin{array}{l}14 \\
18\end{array}$ & $\begin{array}{r}3 \\
20\end{array}$ & $\begin{array}{r}0 \\
12\end{array}$ & $\begin{array}{l}6 \\
0 \\
3\end{array}$ & $\begin{array}{l}0 \\
0 \\
0\end{array}$ & $\begin{array}{l}8 \\
5 \\
0\end{array}$ & $\begin{array}{l}0 \\
0\end{array}$ & $\begin{array}{r}10 \\
8\end{array}$ & $\begin{array}{l}0 \\
0 \\
0\end{array}$ & $\begin{array}{l}6 \\
6\end{array}$ & $\begin{array}{l}0 \\
0\end{array}$ \\
\hline
\end{tabular}

* Dorsal sac of rumen.

Table 5. Comparison of the effect of fatty acid emulsions infused by different routes: total activity in $2 \mathrm{~h}$ periods during which $10 \mathrm{~g}$ different fatty acids were infused by different routes

(Mean values with their standard errors for four sheep per treatment for no. of reticulum contractions; least significant differences derived from error mean square in a two-way analysis of variance are 18.8 for $P=0.05$ and 25.7 for $P=0.01$ )

\begin{tabular}{ccrr}
\hline $\begin{array}{c}\text { Treatment } \\
\text { (fatty acid infused) }\end{array}$ & Route* & Mean & \multicolumn{1}{c}{ SE } \\
\hline Control & 1 & $101 \cdot 5$ & $7 \cdot 03$ \\
$18: 1$ & 1 & 44.3 & 13.05 \\
& 2 & 116.0 & 12.92 \\
& 3 & $55 \cdot 3$ & 4.49 \\
$18: 2$ & 1 & $35 \cdot 3$ & 11.34 \\
& 2 & 109.8 & 9.86 \\
& 3 & 71.0 & 6.14 \\
\hline \hline
\end{tabular}

* 1, Infusion via simple cannula with re-entrant cannula connected normally; 2 , infusion via simple cannula with re-entrant cannula disconnected; 3 , re-entrant cannula disconnected and infusion via distal cannula.

sometimes completely inhibited, that is the intervals between reticulum complexes became longer than $5 \mathrm{~min}$, and then recovered for a time during the infusion. These recoveries of motility after pronounced periods of inhibition were never the result of rumination activity. In some cases motility ceased after a short time and had not resumed by $2 \mathrm{~h}$ after the end of the infusion.

The variable amount of rumination activity, and the reduction in amount during the infusion periods, is shown in Table 3 . When rumination occurred during fatty acid infusions it was usually early in the period. One characteristic of the activity which could be measured, namely the duration of a rumination cycle, appeared to be quite normal. There was never any observation to suggest a disruption of the mechanics of rumination, only a reduction in total quantity reflecting the over-all reduction in forestomach motility.

A further observation made was that rumen contractions were not inhibited to the same extent as the activity of the reticulum. Dorsal sac contractions, usually of reduced amplitude, were often recorded long after the reticulum contractions ceased. In those experiments where ventral sac activity was also recorded, it was clear that the dorsal sac contractions followed closely those of the ventral sac and were thus properly classified as secondary contractions. 
This persistence of some rumen activity is exemplified by the results for the $10 \mathrm{~g}$ infusions in one sheep (no. 229) shown in Table 4 where the activity has been expressed as contractions occurring in each $20 \mathrm{~min}$ of the infusion period. In contrast to the noticeable reduction in amplitude of the rumen contractions those of the reticulum maintained normal amplitude until they stopped.

The results of the second series of experiments are summarized in Table 5. It is clear that reticulum motility was depressed very considerably when emulsions of either oleic acid or linoleic acid were infused so that they were able to reach either the whole of the intestine beyond the cannula $50 \mathrm{~mm}$ from the pylorus (route 1) or only the intestine beyond the iliac flexure (route 3 ). In the latter case (route 3 ) the values for total reticulum activity were not depressed as much as in the former case, though the difference was only statistically significant for linoleic acid. When the infusion was given access only to the proximal part of the duodenum (route 2) there appeared to be a slight, but not significant, increase in reticulum contraction number compared with the control. The mean values were derived from observations in which two sheep showed increased activity, a third sheep showed no change and the fourth showed a reduction, these observations being the same for both infusates.

\section{DISCUSSION}

There was never any indication of a change in motility of the forestomachs as each control infusion was started. Furthermore, there was a marked consistency of reticulum activity shown by the two sheep for which values were available in three different control situations, even though the recordings following re-entrant cannulation were made several months after the others. Constancy of feeding regimen and experimental conditions may have been important factors contributing to this consistency. Evidently, as expected, the infusion rate used $(1 \mathrm{ml} / \mathrm{min})$ did not constitute a significant mechanical stimulus to the duodenum of the sheep which may be subjected to flows of digesta averaging six times this amount (Hogan \& Phillipson, 1960).

A sheep eating approximately $1 \mathrm{~kg}$ hay daily will ingest approximately $20 \mathrm{~g}$ lipid, the fatty acids of which will be mostly saturated by the time they reach the duodenum. Hogan \& Hogan (1976) gave a protected lipid supplement to sheep such that up to $146 \mathrm{~g}$ lipid were ingested daily. Assuming a constant rate of throughput of fatty acids, albeit with an altered composition from that ingested, the sheep's intestines may well have been exposed to up to $6 \mathrm{~g} \mathrm{lipid} / \mathrm{h}$. Half or more of this amount could be in the unsaturated form when diets with protected lipids are fed, according to the investigations reported by Hogan et al. (1972) and Hogan \& Hogan (1976). The infusion rates for single fatty acids used in the present study were 1,2 or $5 \mathrm{~g} / \mathrm{h}$ for $2 \mathrm{~h}$, thereby covering, and perhaps just exceeding, the physiological range. Furthermore, this procedure would be more likely to emulate a physiological process than the injection of $1 \mathrm{~g}$ fatty acid in approximately $1 \mathrm{~min}$, the procedure used by Ehrlein \& Hill (1970).

Clearly, infusion of 3 and $5 \mathrm{~g}$ fatty acid/h caused very marked inhibitions of reticulo-rumen motility. The failure of the $1 \mathrm{~g} / \mathrm{h}$ infusions to produce statistically-significant over-all reductions of motility should not obscure the fact that short periods of inhibition of motility did occur during these infusions. The results in Table 2 do not support the idea that the extent of saturation affects the inhibitory potency either during the infusion period or during the subsequent $2 \mathrm{~h}$. Tidwell \& Cameron (1942) suggested that less saturated fats had a greater inhibitory effect on simple stomach motility, but careful examination of their results shows only a sharp difference betwen the grouped results for saturated and the grouped results for unsaturated fats. McLeay \& Fitzgerald (1982), investigating the effect of intraduodenal fatty acids on ovine gastric secretion, were unable to show a significant difference in inhibitory influence betwen oleic, linoleic and linolenic acids. 
There was a reduced amount of rumination activity in parallel with the reduced reticulum activity. The triphasic reticulum contraction complexes recorded appeared normal and the cycle duration (Table 3 ) did not show any abnormality. Neither was there any indication of abnormality in the rumination processes as judged by direct observation of the sheep.

The finding of Titchen et al. (1966) that the rumen was less susceptible to inhibition than the reticulum was confirmed. An example of the persistence of rumen contractions in one sheep is shown in Table 4. Examination of recordings which included a rumen ventral sac balloon indicated that these were the secondary type of contractions which might well have been associated with eructation of gases. This raises once again the question of how the neuronal networks controlling secondary cycles differ from those dealing with primary cycles whether at rest or rumination.

There was usually greater variation in reticulum activity between animals when given fatty acids than on control days. This is evident from the ranges shown in Table 2. This may in part be accounted for by the intermittent nature of the propulsive activity of the intestines as described by Bueno et al. (1975). They found that the proximal (ascending) portion of the duodenum tended to act as a reservoir region dilating to receive abomasal contents with propulsion from this region occurring erratically. The emulsion was being added to the existing gut contents, not perfusing an isolated and previously-emptied section of gut, therefore the concentration and rate of delivery of the emulsion to the receptive region of the intestine was probably not constant, even though the pumping rate was constant. Similar fluctuating effects have been reported by Singleton (1951) who recorded the inhibitory effect of intraduodenal oils on abomasal motility of goats, and Smith et al. (1979) in studies of lactic-acid-induced motility changes in sheep.

An attempt to determine the region of the intestine sensitive to the fatty acid emulsion was the object of the second series of experiments using four sheep, each with a simple and a re-entrant duodenal cannula (see Table 5). The slight increase in motility recorded when the duodenum only as far as the iliac flexure was perfused with emulsion was probably the result of not returning to the distal cannula an amount of gut contents equivalent to that flowing out of the proximal part of the re-entrant loop (Hogan \& Phillipson, 1960). Nevertheless, when oleic or linoleic emulsions were pumped into the distal cannula with drainage of contents from the proximal cannula occurring there was a clear inhibitory effect on reticulum motility. That it was slightly less than the effect of similar infusions given through the cannula just beyond the pylorus was probably because of the excitatory effect of the emptying from the proximal duodenum. On the other hand, it might point to there being some inhibitory influence of the proximal part of the duodenum which in the case of perfusion of that region alone was more than obscured by the emptying effect. Alternatively there may be receptors in the duodenum which would not be influenced by lipid unless in a micellar form. In these experiments there would not be an opportunity for micelle formation because the bile and pancreatic juice enter near the end of the perfused region. It should be pointed out that emulsions as used in this work do not exert any osmotic effect. They give a zero reading in a freezing-point-depression osmometer and do not cause water movement across a dialysis membrane.

No other work involving fatty acid administration to selected areas of the intestine of ruminants has been reported. In dogs neither the first $50 \mathrm{~mm}$ of the duodenum (Cooke \& Clark, 1976) nor the whole of the duodenum (Cooke, 1977) appeared to be sensitive to sodium oleate, the only lipid substance tested by these workers. Infusion through the jejunum onwards of $20 \mathrm{~mm}$-sodium oleate at $200 \mathrm{ml} / \mathrm{h}$ was effective in reducing the rate of gastric emptying (Cooke, 1977). Similarly, working with human patients, Knoop et al. (1979) suggested the presence of jejunal receptors for fat because the inhibitory effect of fat was the same in normal people and Billroth II patients who have antrectomy, gastro-jejunostomy and vagotomy. 
Another point to consider is that the lack of supply of bile and pancreatic juice to the jejunum and beyond when the re-entrant cannula was disconnected would bring about a reduction in lipid absorption. From the work of Harrison \& Leat (1972) it could be expected that the rate of fat absorption would be at least halved after $2 \mathrm{~h}$ without addition of bile and pancreatic juice. It is a moot point whether such reduced fat absorption would alter the sensitivity of the inhibitory mechanism. Tidwell \& Cameron (1942) suggested that inhibition of simple-stomach motility was correlated with the rate of absorption of fat which was in turn related to saturation, but gradations of effect correlating with the extent of unsaturation were not apparent in their work.

The onset of the inhibitory effect was gradual, even in the second series of experiments when infusions were made into the distal cannula, and this suggests involvement of a hormonal rather than a purely neural mechanism mediating the response to fatty acids. It has been shown (Johnson \& Grossman, 1971) that fats are the most potent stimulators of the release of cholecystokinin (CCK). That CCK can reduce forestomach motility and, in particular, the frequency rather than the amplitude, has been demonstrated by Grovum (1981). In this work, as noted in the results section, reticulum contraction amplitude was normal until the contractions actually stopped. Bunnett \& Harrison (1979) have shown the presence of cells having gastrin-like immunoreactivity throughout the first half of the small intestine and suggest on the basis of cross reaction that it is likely that the cells demonstrated in the jejunum will be predominantly CCK producers. All these considerations therefore point to the probability that the inhibition of forestomach motility in response to long-chain unsaturated fatty acids was due to release of a humoural agent, probably CCK, from the intestine excluding the duodenum. It will be necessary to repeat this work when a reliable assay for ovine CCK becomes available and an attempt should be made to pin-point more exactly the sensitive regions of the intestine and the necessity or otherwise for bile and pancreatic juice to be present.

S.A.O. was financed by the Sudanese Government. The authors wish to thank J. Stowell and D. N. Jones for technical assistance.

\section{REFERENCES}

Bines, J. A., Brumby, P. E., Storry, J. E., Fulford, R. J. \& Braithwaite, G. D. (1978). Journal of Agricultural Science 91, 135-150.

Bueno, L., Fioramonti, J. \& Ruckebusch, Y. (1975). Journal of Physiology 249, 69-85.

Bunnett, N. W. \& Harrison, F. A. (1979). Journal of Physiology 295, $19 P$.

Christie, W. W. (1978). Progress in Lipid Research 17, 111-205.

Cooke, A. R. (1977). Gastroenterology 72, 875-880.

Cooke, A. R. \& Clark, E. D. (1976). Gastroenterology 70, 550-555.

Dinius, D. A., Oltjen, R. R., Lyon, C. K., Kohler, G. O.\& Walker, H. G. (1974). Journal of Animal Science 39, $124-133$.

Ehrlein, H.-J. \& Hill, H. (1970). Zentralblatt für Veterinärmedizin 17, 498-516.

Faichney, G. T., Scott, T. W. \& Cook, L. J. (1973). Australian Journal of Biological Science 26, 1179-1188.

Garton, G. A. (1977). International Review of Biochemistry. Biochemistry of Lipids II, volume 14. [T. W. Goodwin, editor]. Baltimore: University Park Press.

Grovum, W. L. (1981). British Journal of Nutrition 45, 183-201.

Harrison, F. A. (1974). Journal of Physiology 242, $20 P$.

Harrison, F. A. \& Leat, W. M. F. (1972). Journal of Physiology 225, 565-576.

Hogan, J. P., Connell, P. J. \& Mills, S. C. (1972). Australian Journal of Agricultural Research 23, 87-95.

Hogan, J. P. \& Hogan, R. M. (1976). Australian Journal of Agricultural Research 27, 129-138.

Hogan, J. P. \& Phillipson, A. T. (1960). British Journal of Nutrition 14, 147-155.

Jarrett, I. G. (1948). Journal of the Council for Scientific and Industrial Research, Australia 21, 311-315.

Johnson, L. R. \& Grossman, M. I. (1971). Gastroenterology 60, 120-144.

Knoop, H. S., Long, W. B., Alavi, A. \& Hansell, J. R. (1979). Gastroenterology 77, 997-1000.

McLeay, L. M. (1967). Control of abomasal secretion in the sheep. M. Agric. Sci. Thesis, Massey University, New Zealand. 
McLeay, L. M. \& Fitzgerald, J. M. (1982). American Journal of Physiology 243, G127-G133.

Ogilvie, B. M., McClymont, G. L. \& Shorland, F. B. (1961). Nature 190, 725-726.

Singleton, A. G. (1951). Journal of Physiology 115, 73P.

Smith, C. M., Krishnamurti, C. R. \& Kitts, W. D. (1979). Canadian Journal of Animal Science 59, $255-263$.

Snedecor, G. W. \& Cochran, W. G. (1967). Statistical Analysis, 6th ed. Ames, Iowa: The Iowa State University Press.

Tidwell, H. C. \& Cameron, E. S. (1942). Bulletin of the Johns Hopkins Hospital 70, 362-369.

Titchen, D. A., Reid, C. S. W. \& Vlieg, P. (1966). Proceedings of the New Zealand Society for Animal Production 26, 36-51.

Wilcoxon, F. \& Wilcox, R. A. (1964). Some Rapid, Approximate Statistical Procedures. New York: Lederle Laboratories. 